\title{
Nasopharyngeal Cancer pN3b TNM Finding v6
}

National Cancer Institute

\section{Source}

National Cancer Institute. Nasopharyngeal Cancer pN3b TNM Finding v6. NCI

Thesaurus. Code C64479.

Nasopharyngeal cancer with metastasis to lymph nodes which are whole or in part in the supraclavicular fossa. This includes caudal portions of Levels IV and V lymph nodes. All cases with lymph nodes (whole or in part) in the supraclavicular fossa are considered N3b. (from AJCC 6th Ed.) 